\title{
Application of ABR in pathogenic neurovascular compression of the 8th cranial nerve in vestibular paroxysmia
}

\author{
Huiying Sun ${ }^{1} \cdot$ Xu Tian $^{1} \cdot$ Yang Zhao ${ }^{1} \cdot$ Hong Jiang ${ }^{1} \cdot$ Zhiqiang Gao $^{1} \cdot$ Haiyan $\mathrm{Wu}^{1}(\mathbb{0}$
}

Received: 6 December 2021 / Accepted: 14 February 2022 / Published online: 5 March 2022

(c) The Author(s) 2022

\begin{abstract}
Purpose To investigate the clinical value of electrophysiological tests in indicating pathogenic vascular contact of the 8th nerve in definite vestibular paroxysmia (VP) cases to provide a reference for decompression surgery.

Methods We retrospectively analyzed patients who had vertigo, unilateral tinnitus, or hearing loss and exhibited vascular contact of the 8th cranial nerve by MRI. Participants were classified into the VP or non-VP group according to the criteria of the Bárány Society in 2016. The demographic characteristics and audiological and electrophysiological test results of the two groups were compared. Receiver operating characteristic (ROC) curves were calculated for ABR to determine the best parameters and cutoff values to predict the existence of pathological neurovascular contact in VP.

Results Thirteen patients in the VP group and 66 patients in the non-VP group were included. VP patients had longer interpeak latency (IPL) I-III and wave III latency compared to non-VP patients $(p<0.001 ; p<0.001)$. According to the ROC analyses, IPL I-III and wave III latency were the best indicators for the diagnosis of VP. The optimal cutoff for IPL I-III was $2.3 \mathrm{~ms}$ (sensitivity $84.6 \%$, specificity $95.5 \%$ ), and that for wave III latency was $4.0 \mathrm{~ms}$ (sensitivity $92.3 \%$, specificity $77.3 \%$ ). There were no differences in the PTA, caloric test, o-VEMP, or c-VEMP results between the two groups.

Conclusion Prolonged IPL I-III and the wave III latency of ABR strongly suggested that vascular contact of the 8th cranial nerve was pathological, which may provide some references for microvascular decompression surgery of VP.
\end{abstract}

Keywords Vestibular paroxysmia $\cdot$ Neurovascular compression $\cdot$ Auditory brainstem response $\cdot$ Magnetic resonance imaging

\section{Introduction}

Neurovascular cross-compression (NVCC) in the cerebellopontine angle (CPA) or internal acoustical canal (IAC) may cause vertigo, tinnitus, or hearing loss $[13,14,25]$. Vestibular paroxysmia (VP), previously termed "disabling positional vertigo," is a certain kind of NVCC of the 8th cranial nerve that results in spinning or non-spinning dizziness, with or without ear symptoms such as tinnitus, sensorineural

This article is part of the Topical Collection on Neurosurgery general

Haiyan Wu

ywjwhy@sina.com

1 Department of Otorhinolaryngology, Perking Union Medical College Hospital, Chinese Academy of Medical Sciences Peking Union Medical College, No.1 Shuaifuyuan,Wangfujing, Dongcheng District, 100730 Beijing, China hearing loss, and acoustic hypersensitivity [4]. The diagnostic criteria for VP were defined by the Classification Committee of the Bárány Society in 2016 [27]. The prevalence of VP is relatively low, at less than 1 in 2000 people [27], and $\mathrm{VP}$ is frequently reported from 40 to 50 years of age [3, 28]. A low dose of carbamazepine or oxcarbazepine is the preferred treatment for VP. However, some patients do not respond well to pharmacotherapy or cannot tolerate the side effects of these drugs [32]. For these patients, microvascular decompression surgery is a choice that was introduced for hemifacial spasms, trigeminal neuralgia, and refractory vertigo $[11,14,21]$. But this surgery may lead to serious postoperative complications such as hearing loss, facial palsy, and cerebrospinal fluid leakage [22,31], and the surgical indications remain uncertain in VP [24]. To avoid unnecessary surgeries, adequate preoperative assessments providing evidence for pathogenic neurovascular contact are essential prerequisites. 
Over $95 \%$ of VP patients show neurovascular contact on magnetic resonance imaging (MRI) with relatively high sensitivity (nearly $100 \%$ ) and low specificity $(65 \%)[1,26]$. It is difficult to determine if neurovascular contact is problematic or if it leads to the onset of VP because some patients with contacts on MRI are asymptomatic. Previous studies have reported some changes in electrophysiological tests, such as auditory brainstem response (ABR), caloric tests, and vestibular evoked myogenic potentials (VEMPs) $[5,9,16]$, but their clinical value in determining whether the neurovascular contact shown in radiology is pathological remains uncertain and controversial. Thus, this paper aimed to investigate the outcomes of these electrophysiological tests and to assess the possibility of utilizing these tests as an indicator for neurovascular conflict in VP patients with neurovascular contact demonstrated on MRI, providing some objective references for microvascular decompression surgery and aiding in decision-making for potential candidates. This study was exempted from the Institutional Review Board review by the Medical Ethics Committee of Peking Union Medical College Hospital (S-K1695).

\section{Materials and methods}

\section{Participants}

The medical charts of patients diagnosed with vertigo, unilateral subjective tinnitus, or unilateral hearing loss with vascular contact of the 8th cranial nerve on the affected side confirmed by MRI and presented at the Department of Otorhinolaryngology in Peking Union Medical College Hospital from September 2019 to November 2020 were retrospectively analyzed. The exclusion criteria were otitis media, tumor of the ear or cerebellopontine angle, and head or ear trauma. Patients who met the criteria for definite VP by the Bárány Society in 2016 [27] were classified into the VP group, and the others were classified into the non-VP group. The criteria for definite VP were as follows: (1) at least ten attacks of spontaneous spinning or nonspinning vertigo; (2) duration less than $1 \mathrm{~min}$; (3) stereotyped phenomenology in a particular patient; (4) response to treatment with carbamazepine/oxcarbazepine; and (5) not better explained by another diagnosis. The affected side of all the patients was verified according to the comprehensive considerations of symptoms, hearing level, and results of electrophysiological testing.

The demographic characteristics of all the patients were collected. Tinnitus was recorded as typewriter (staccato, not pulse synchronous), pulsatile, and persistent (low- or highfrequency) types. Vertigo was divided into acute, episodic, and chronic vestibular syndromes [2]. The hearing level was assessed according to the mean value of the thresholds of
$0.5,1,2$, and $4 \mathrm{kHz}$ by pure tone audiometry (PTA). All participants underwent vestibular electrophysiological evaluations, including ABR, caloric test, ocular vestibular evoked myogenic potential (o-VEMP), and cervical vestibular evoked myogenic potential (c-VEMP), in a sound-proof booth. The ABR results were further analyzed according to the criteria by Møller [22], including latencies of waves I, III, and V, interpeak latency (IPL) I-III and IPL III-V, and IPL I-III difference and IPL III-V difference between the affected side and normal side.

Neurovascular contact was defined as the absence of a cerebrospinal fluid signal gap between the nerve and the specific vessel on MRI (high-resolution T2W-3D-DRIVE sequence) [1]. Neurovascular contact was further classified into 3 types according to the Chavda system [20]: (1) type I: the anterior inferior cerebellar artery (AICA) loop lies within the CPA but does not enter the IAC; (2) type II: the AICA loop enters the IAC but does not extend more than $50 \%$ of the long axis of the IAC; and (3) type III: the AICA loop extends more than $50 \%$ into the IAC.

\section{Statistical analysis}

Data were analyzed using SPSS v. 23.0 (Chicago, IL, USA), and a $p$ value of $<0.05$ (two-tailed) was considered statistically significant. Normally distributed continuous variables are reported as the mean \pm standard deviation (SD), and non-normally distributed data are reported as the median and interquartile range (IQR). Continuous data were analyzed using Student's $t$-test or the Mann-Whitney $U$ test, and categorical data were analyzed using a $2 \times 2$ contingency table and Fisher's exact test. Receiver operating characteristic (ROC) curves were calculated for ABR results to determine the most qualified variables, and the cutoff values were determined by maximizing the Youden index for sensitivity and specificity optimization to predict injury to the 8th cranial nerve in VP patients with neurovascular contact.

\section{Results}

\section{Demographic characteristics}

Thirteen patients with VP (8 [61.5\%] males, 5 [38.5\%] females) and 66 patients as controls (non-VP) were enrolled. In the VP group, twelve patients received oral oxcarbazepine, and one patient received carbamazepine because of nausea and vomiting with oxcarbazepine. All VP patients have received satisfactory pharmacological treatment efficacy thus far. Specifically, vertigo was controlled, and most typewriter tinnitus disappeared. However, in nine patients $(69.2 \%)$, vertigo relapsed after discontinuation of the drug. 
The symptoms could be controlled again after restarting the medication at the original dose, and these patients adhered to drug therapy. The average follow-up time was $13.2 \pm 5.8$ months, ranging from 10 to 32 months. Detailed information on the VP patients is shown in Table 1.

The average age in the VP group was $55.8 \pm 14.7$ years, which was higher than that in the non-VP group $(45.7 \pm 11.4$ years $)(p=0.016)$. A total of $76.9 \%$ of VP patients had typewriter tinnitus, but none of the patients in the control group experienced this type of tinnitus $(p<0.001)$. No obvious differences were found in vertigo type between the VP and non-VP groups $(p=0.732)$. Moreover, there were no significant differences in sex, duration, or laterality between the two groups $(p>0.05)$ (Table 2).

\section{ABR results}

Regarding the ABR results, there was no difference in the wave I latency of the affected side between the two groups $(p=0.530)$, but the wave III latency in the VP group was longer than that in the non-VP group $(p<0.001)$. Accordingly, the wave interval I-III in the VP group was longer than that in the non-VP group $(p<0.001)$. There was also a significant difference in wave $\mathrm{V}$ latency between the two groups $(p<0.001)$, but wave interval III-V showed no statistically significant difference ( $p=0.456$, see Table 2).

When comparing the differences between the affected and normal sides within the VP group, the wave III latency and IPL I-III of the affected side were longer than those of the normal side $(p=0.006 ; p=0.001)$. No difference was observed in wave I and V latency or IPL III-V $(p>0.05$, see Table 3).

According to the criteria by Møller [22], a total of $84.6 \%$ of the VP patients and $4.5 \%$ of the non-VP controls had an IPL I-III $\geq 2.3 \mathrm{~ms}(p<0.001)$. Furthermore, an IPL I-III difference between the affected side and the normal side $\geq 0.2 \mathrm{~ms}$ was more frequent in the VP group than in the non-VP group $(p=0.001)$. None of the VP patients had a contralateral IPL III-V $\geq 2.2 \mathrm{~ms}$ or IPL III-V difference $\geq 0.2 \mathrm{~ms}$, with no differences compared with the control group (Table 4).

After comparing the areas under the curve (AUCs) of wave latencies (affected side: I, III, and V) and wave intervals (affected side: I-III and III-V; normal side: III-V) by ROC analysis, we identified IPL I-III and wave III latency as the best predictive parameters for VP with neurovascular contact by MRI in our dataset (AUC $>0.9$, see Table 5 and Supplemental Table 1). According to the ROC analyses, the optimal cutoff for IPL I-III was $2.3 \mathrm{~ms}$ (sensitivity $84.6 \%$, specificity $95.5 \%$ ), and wave III latency was $4.0 \mathrm{~ms}$ (sensitivity $92.3 \%$, specificity $77.3 \%$ ) (Fig. 1).

\section{Other audiologic, vestibular, and imaging measurements}

The average hearing threshold of the VP group was $34.0 \pm 20.0 \mathrm{~dB}$ HL and that of the non-VP group was $33.3 \pm 24.4 \mathrm{~dB}$ HL $(p=0.605)$. There were no significant differences in the canal paresis or directional preponderance of the caloric test $(p=0.681, p=0.373)$. The latencies and amplitudes of o-VEMP and c-VEMP between the two groups showed no statistically significant differences $(p>0.05)$. Moreover, no difference in neurovascular contact type on MRI was observed between the VP and non-VP groups $(p=0.579)($ Table 2$)$.

\section{Discussion}

VP is a rare episodic peripheral vestibular disorder that has a substantial impact on the quality of life of patients. Vascular compression of the cochleovestibular nerve is the widely accepted pathogenesis of VP. The symptoms are triggered by ephaptic transmission between demyelinated axons due to the pulsatile compression of the responsible vessel [19, 23]. A loop of the AICA seems to be the most relevant vessel (77.8-100\%), followed by the posterior inferior cerebellar artery (PICA), the vertebral artery and veins $[8,10,26]$. Radiology is essential for a clear view of neurovascular contact, but the pressure of the vessels on nerves cannot be confirmed only by imaging. The present study was designed to analyze the value of electrophysiological tests in indicating pathogenic neurovascular contact in definite VP cases, with the goal of providing some objective references when decompression surgery is considered.

Previous articles reported some characteristics of ABR in VP patients, and the prolongation of IPL I-III was identified as a general and prevalent phenomenon [22, 24]. In the present study, we primarily found significant prolongation of IPL I-III and wave III and V latency in the VP group compared with the non-VP group. IPL III-V showed no statistically significant difference between the two groups ( $p=0.456)$, indicating that the elongation of wave $\mathrm{V}$ latency in the VP group was the result of prolonged wave III. Additionally, according to the AUCs of these variables by ROC analysis, only IPL I-III and wave III latency were chosen for further assessment. Besides, we found that IPL I-III was the optimal parameter for diagnosing VP with satisfactory sensitivity and specificity (specificity $=95.5 \%$; sensitivity $=84.6 \%$ ), followed by wave III latency (specificity $=77.3 \%$; sensitivity $=92.3 \%$ ). As the absence of wave I was not rare in VP patients, we found that a prolonged wave III latency had a similar indicative value as a prolonged IPL I-III. The results suggested that neurovascular contact was more likely to be pathological in patients with VP-like 


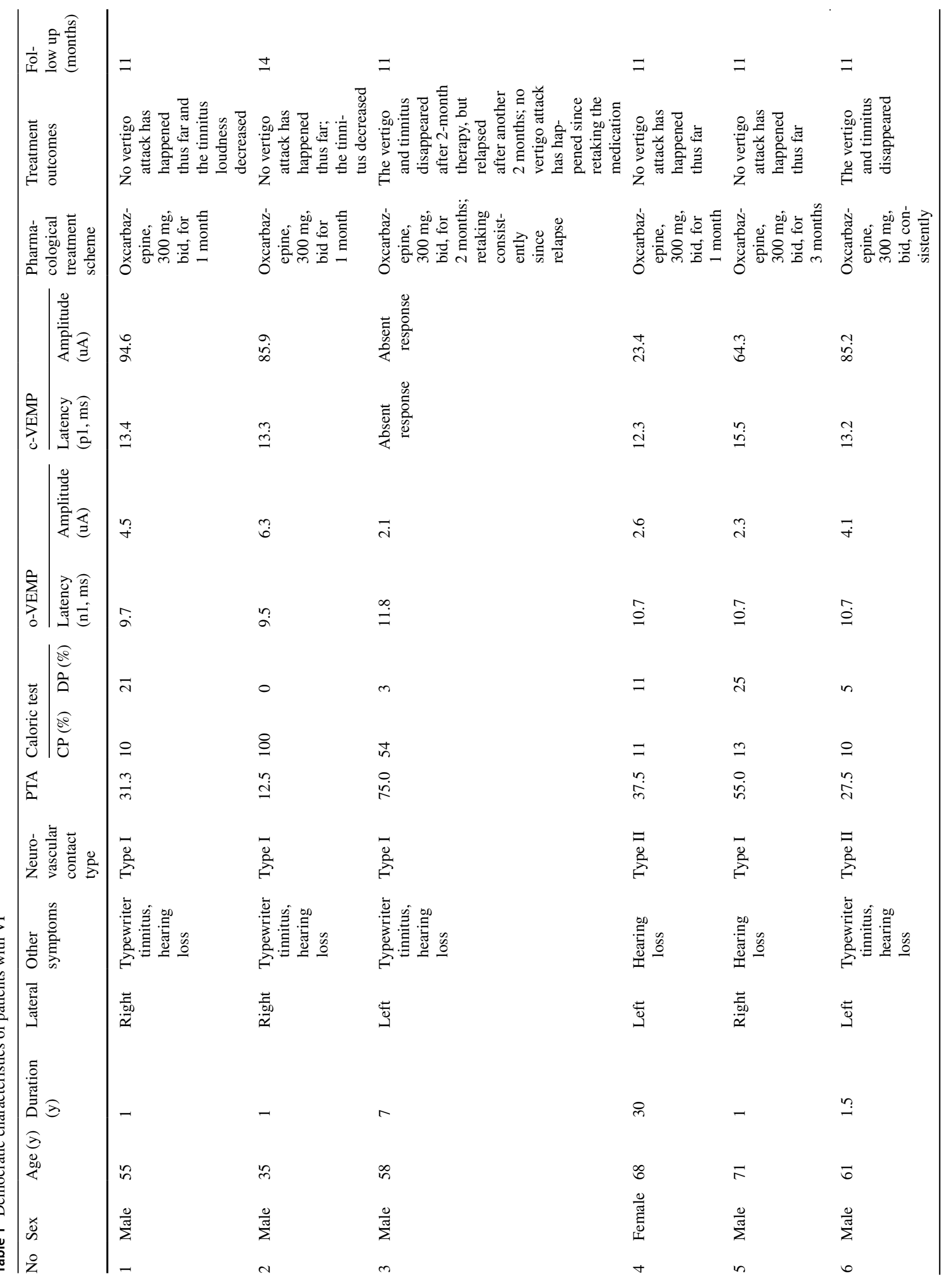




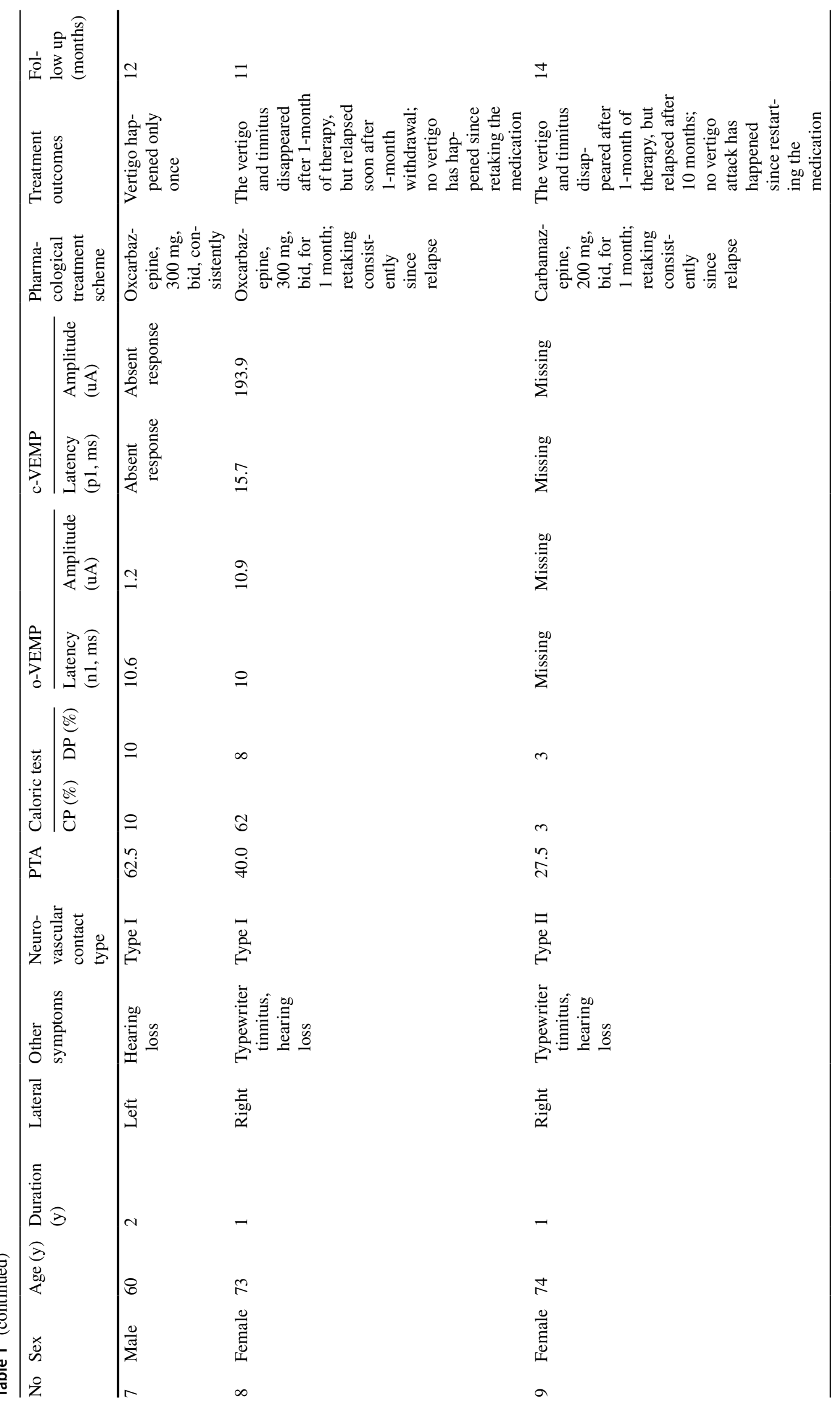




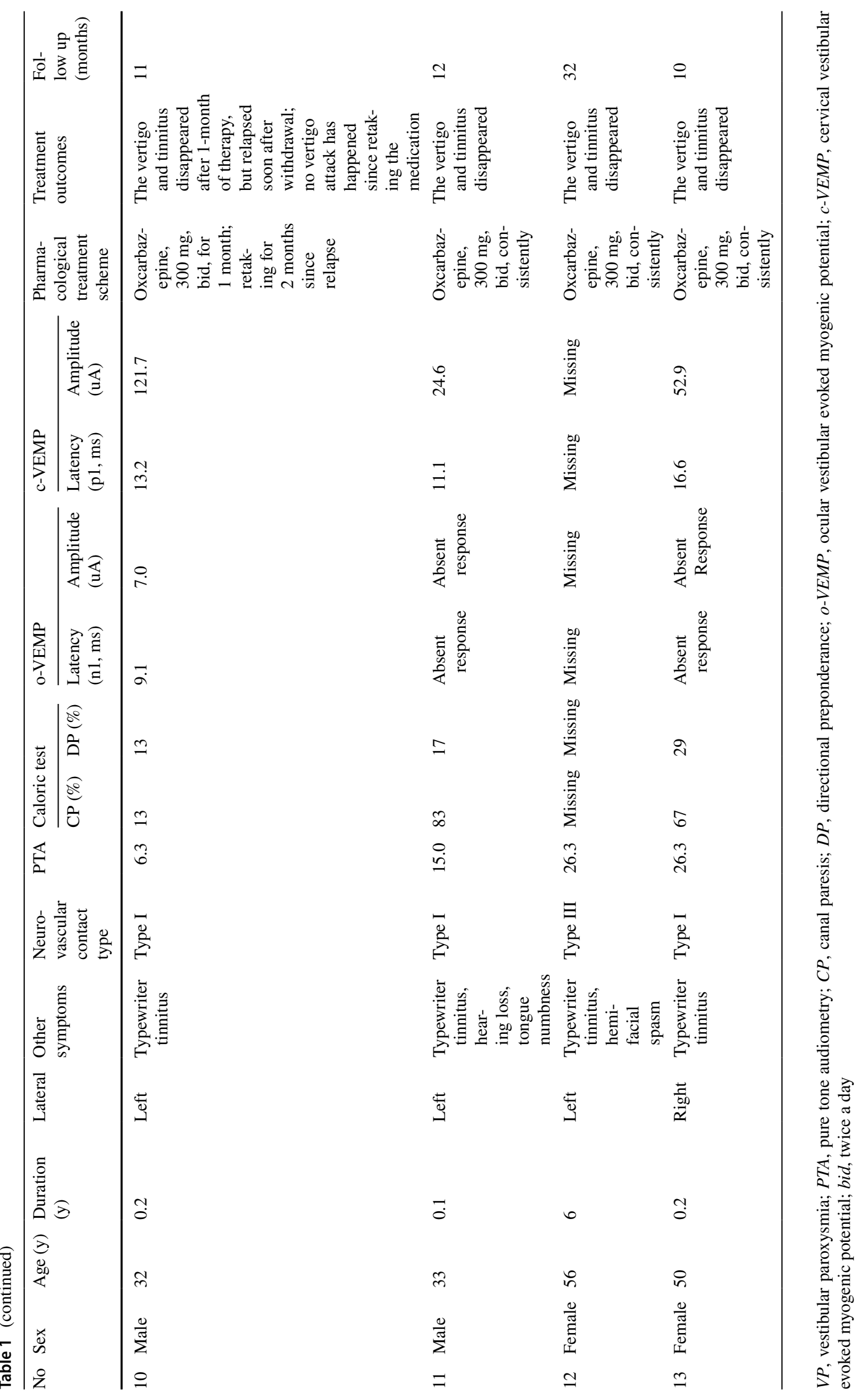


Table 2 Comparison between patients with VP and patients without VP

\begin{tabular}{|c|c|c|c|}
\hline Valuables & Non-VP $(n=66)$ & $\mathrm{VP}(n=13)$ & $p$ \\
\hline \multicolumn{4}{|l|}{ Gender $(n, \%)$} \\
\hline Male & $23(34.8)$ & $8(61.5)$ & \multirow[t]{2}{*}{0.072} \\
\hline Female & $43(65.2)$ & $5(38.5)$ & \\
\hline Age $($ mean $\pm S D, y)$ & $45.7 \pm 11.4$ & $55.8 \pm 14.7$ & $0.016^{*}$ \\
\hline Duration (mean $\pm \mathrm{SD}, \mathrm{y})$ & $5.1 \pm 7.3$ & $4.3 \pm 8.4$ & 0.304 \\
\hline \multicolumn{4}{|l|}{ Lateral $(n, \%)$} \\
\hline Left & $27(40.9)$ & $7(53.8)$ & \multirow[t]{2}{*}{0.389} \\
\hline Right & $39(59.1)$ & $6(46.2)$ & \\
\hline \multicolumn{4}{|l|}{ Tinnitus $(n, \%)$} \\
\hline Typewriter tinnitus & $0(0.0)$ & $10(76.9)$ & \multirow[t]{3}{*}{$<0.001^{*}$} \\
\hline Pulsatile tinnitus & $2(3.0)$ & $0(0.0)$ & \\
\hline Persistent tinnitus (low- or high- frequency) & $21(31.8)$ & $0(0.0)$ & \\
\hline \multicolumn{4}{|l|}{ Vertigo $(n, \%)$} \\
\hline Acute vestibular syndrome & $6(9.1)$ & $0(0.0)$ & \multirow[t]{3}{*}{0.732} \\
\hline Episodic vestibular syndrome & $47(71.2)$ & $13(100.0)$ & \\
\hline Chronic vestibular syndrome & $2(3.0)$ & $0(0.0)$ & \\
\hline \multicolumn{4}{|l|}{ Neurovascular contact type $(n, \%)$} \\
\hline Type I & $41(62.1)$ & $9(69.2)$ & \multirow[t]{3}{*}{0.579} \\
\hline Type II & $22(33.3)$ & $3(23.1)$ & \\
\hline Type III & $3(4.6)$ & $1(7.7)$ & \\
\hline $\mathrm{PTA}($ mean $\pm \mathrm{SD}, \mathrm{dB} H \mathrm{HL})$ & $33.3 \pm 24.4$ & $34.0 \pm 20.0$ & 0.605 \\
\hline \multicolumn{4}{|l|}{ Caloric test } \\
\hline Missing $(n, \%)$ & $15(22.7)$ & $1(7.7)$ & \\
\hline Canal paresis $($ mean $\pm \mathrm{SD}, \%)$ & $31.9 \pm 25.4$ & $36.3 \pm 34.5$ & 0.681 \\
\hline Directional preponderance (mean $\pm \mathrm{SD}, \%)$ & $14.8 \pm 9.9$ & $12.0 \pm 9.1$ & 0.373 \\
\hline \multicolumn{4}{|l|}{ o-VEMP } \\
\hline Missing $(n, \%)$ & $9(13.6)$ & $2(15.4)$ & \\
\hline Absent response $(n, \%)$ & $4(6.1)$ & $2(15.4)$ & \\
\hline Response $(n, \%)$ & $53(80.3)$ & $9(69.2)$ & \\
\hline Latency $($ mean $\pm \mathrm{SD}, \mathrm{ms})$ & $10.2 \pm 0.9$ & $7.1 \pm 5.0$ & 0.212 \\
\hline Amplitude (mean $\pm \mathrm{SD}, \mathrm{uA}$ ) & $3.3 \pm 2.4$ & $4.6 \pm 3.1$ & 0.210 \\
\hline \multicolumn{4}{|l|}{ c-VEMP } \\
\hline Missing $(n, \%)$ & $9(13.6)$ & $2(15.4)$ & \\
\hline Absent response $(n, \%)$ & $8(12.1)$ & $2(15.4)$ & \\
\hline Response $(n, \%)$ & $49(74.2)$ & $9(69.2)$ & \\
\hline Latency $($ mean $\pm \mathrm{SD}, \mathrm{ms})$ & $13.8 \pm 2.1$ & $13.8 \pm 1.8$ & 0.723 \\
\hline Amplitude $($ mean $\pm \mathrm{SD}, \mathrm{uA})$ & $64.9 \pm 37.6$ & $83.0 \pm 52.7$ & 0.316 \\
\hline \multicolumn{4}{|l|}{$\mathrm{ABR}$} \\
\hline \multicolumn{4}{|l|}{ Affected side } \\
\hline I wave latency $($ mean $\pm S D, m s)$ & $1.7 \pm 0.2$ & $1.7 \pm 0.1$ & 0.530 \\
\hline Absent response $(n, \%)$ & $6(9.1)$ & $2(15.4)$ & \\
\hline Response $(n, \%)$ & $60(90.9)$ & $11(84.6)$ & \\
\hline III wave latency (mean \pm SD, ms) & $3.9 \pm 0.2$ & $4.3 \pm 0.3$ & $<0.001 *$ \\
\hline Absent response $(n, \%)$ & $3(4.5)$ & $0(0.0)$ & \\
\hline Response $(n, \%)$ & $63(95.5)$ & $13(100.0)$ & \\
\hline $\mathrm{V}$ wave latency $($ mean $\pm \mathrm{SD}, \mathrm{ms})$ & $5.7 \pm 0.2$ & $6.1 \pm 0.3$ & $<0.001^{*}$ \\
\hline Absent response $(n, \%)$ & $2(3.0)$ & $0(0.0)$ & \\
\hline Response $(n, \%)$ & $64(97.0)$ & $13(100.0)$ & \\
\hline IPL I-III (mean \pm SD, ms) & $2.1 \pm 0.1$ & $2.5 \pm 0.3$ & $<0.001 *$ \\
\hline IPL III-V (mean \pm SD, ms) & $1.8 \pm 0.2$ & $1.8 \pm 0.1$ & 0.456 \\
\hline \multicolumn{4}{|l|}{ Normal side } \\
\hline IPL I-III (mean \pm SD, ms) & $2.1 \pm 0.1$ & $2.2 \pm 0.1$ & 0.062 \\
\hline IPL III-V (mean \pm SD, ms) & $1.9 \pm 0.2$ & $1.9 \pm 0.2$ & 0.788 \\
\hline
\end{tabular}

${ }^{*} p<0.05$

$V P$, vestibular paroxysmia; $P T A$, pure tone audiometry; $o$-VEMP, ocular vestibular evoked myogenic potential; $c$-VEMP, cervical vestibular evoked myogenic potential; $A B R$, auditory brainstem response; $I P L$, interpeak latency 
Table 3 Comparison of ABR results between the normal side and affected side of the patients in the VP group $(n=13)$

\begin{tabular}{llll}
\hline $\begin{array}{l}\text { Valuables (mean } \pm \mathrm{SD}, \\
\mathrm{ms})\end{array}$ & Normal side & Affected side & $p$ \\
\hline I wave latency & $1.8 \pm 0.2$ & $1.7 \pm 0.1$ & 0.165 \\
III wave latency & $4.0 \pm 0.1$ & $4.3 \pm 0.3$ & $0.006^{*}$ \\
V wave latency & $5.9 \pm 0.2$ & $6.1 \pm 0.3$ & 0.082 \\
IPL I-III & $2.2 \pm 0.1$ & $2.5 \pm 0.3$ & $0.001^{*}$ \\
IPL III-V & $1.9 \pm 0.2$ & $1.8 \pm 0.1$ & 0.236 \\
\hline
\end{tabular}

${ }^{*} p<0.05$

$V P$, vestibular paroxysmia; $I P L$, interpeak latency

clinical symptoms accompanied by either IPL I-III $\geq 2.3 \mathrm{~ms}$ or wave III latency $\geq 4.0 \mathrm{~ms}$ on the affected side.

More patients in the VP group (84.6\%) had a value of IPL $\mathrm{I}-\mathrm{III} \geq 2.3 \mathrm{~ms}$ than patients in the non-VP group (4.5\%) in this study. An absolute value of IPL I-III exceeding $2.3 \mathrm{~ms}$ was one of the Møller's criteria for cochleovestibular compression syndrome in disabling positional vertigo and tinnitus [22], which coincides with the cutoff threshold determined in this study. The reasons for this similarity may be as follows: (1) due to the

Table 4 Comparison of ABR results between the VP group and the non-VP group using Møller criteria

\begin{tabular}{|c|c|c|c|}
\hline Variables & Non-VP $(n=66)$ & $\mathrm{VP}(n=13)$ & $p$ \\
\hline \multicolumn{4}{|c|}{$\begin{array}{l}\text { IPL I-III of affected side } \\
\quad(n, \%)\end{array}$} \\
\hline Absent response & $6(9.1)$ & $2(15.4)$ & $<0.001 *$ \\
\hline$<2.3 \mathrm{~ms}$ & $57(86.4)$ & $0(0.0)$ & \\
\hline$\geq 2.3 \mathrm{~ms}$ & $3(4.5)$ & $11(84.6)$ & \\
\hline \multicolumn{4}{|c|}{$\begin{array}{l}\text { IPL III-V of normal side } \\
(n, \%)\end{array}$} \\
\hline Absent response & $0(0.0)$ & $1(7.7)$ & 0.304 \\
\hline$<2.2 \mathrm{~ms}$ & $65(98.5)$ & $12(92.3)$ & \\
\hline$\geq 2.2 \mathrm{~ms}$ & $1(1.5)$ & $0(0.0)$ & \\
\hline \multicolumn{4}{|c|}{$\begin{array}{l}\text { IPL I-III difference } \\
\text { between the affected } \\
\text { side and normal side } \\
(n, \%)\end{array}$} \\
\hline Absent response & $6(9.1)$ & $3(23.0)$ & $0.001^{*}$ \\
\hline$<0.2 \mathrm{~ms}$ & $56(84.8)$ & $5(38.5)$ & \\
\hline$\geq 0.2 \mathrm{~ms}$ & $4(6.1)$ & $5(38.5)$ & \\
\hline \multicolumn{4}{|c|}{$\begin{array}{l}\text { IPL III-V difference } \\
\text { between the affected } \\
\text { side and normal side } \\
(n, \%)\end{array}$} \\
\hline Absent response & $2(3.0)$ & $1(7.7)$ & 0.498 \\
\hline$<0.2 \mathrm{~ms}$ & $60(90.9)$ & $12(92.3)$ & \\
\hline$\geq 0.2 \mathrm{~ms}$ & $4(6.1)$ & $0(0.0)$ & \\
\hline
\end{tabular}

${ }^{*} p<0.05$

$V P$, vestibular paroxysmia; $I P L$, interpeak latency
Table 5 Analysis of the receiver operating characteristic (ROC) curves

\begin{tabular}{lll}
\hline Variables & AUC & $p$ \\
\hline I wave latency of affected side & 0.473 & 0.782 \\
III wave latency of affected side & 0.928 & $0.000^{*}$ \\
V wave latency of affected side & 0.853 & $0.000^{*}$ \\
IPL I-III of affected side & 0.993 & $0.000^{*}$ \\
IPL III-V of affected side & 0.398 & 0.306 \\
IPL III-V of normal side & 0.573 & 0.460 \\
\hline
\end{tabular}

* $p<0.05$

$I P L$, interpeak latency; $A U C$, area under the curve

rare incidence of VP, the sample size of this study was small, which may influence the values, and (2) the high IPL I-III $(\geq 2.3 \mathrm{~ms}$ ) was not an indicator of VP exclusively but a possible indicator of a lesion or injury of the 8th cranial nerve. The scientific value of this study is twofold: (1) the study focused on VP based on the new definition proposed in 2016, rather than a generic scope of diseases including vertigo and tinnitus, and (2) the present results indicate that wave III latency $\geq 4.0 \mathrm{~ms}$ is an equally significant indicator of VP, useful when wave I is absent, which was not mentioned in Møller's criteria. The contralateral IPL III-V may need to be longer to compensate for the abnormality of the affected side, as explained by De Ridder D. et al. [6]. However, no such differences in the IPL III-V of the normal side between the two groups were discovered, which needs further discussion.

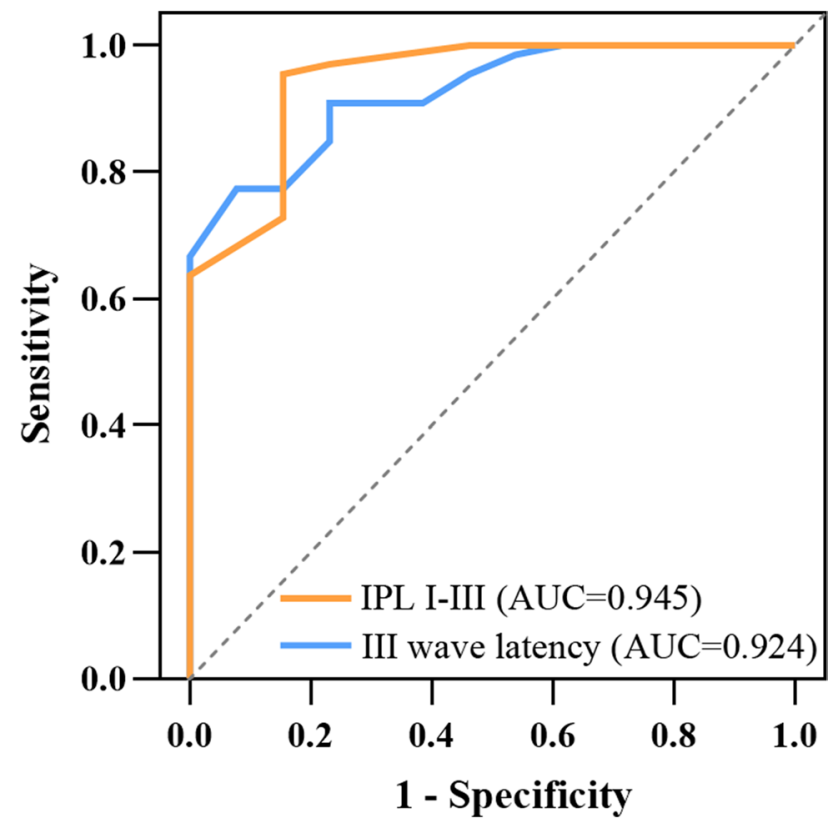

Fig. 1 Receiver operating characteristic curves. Optimal points of IPL I-III and wave III latency were calculated according to the max Youden Index (Youden Index = Sensitivity + Specificity -1$)$ 
There were no differences in the other acoustic and vestibular electrophysiological tests, such as PTA, caloric test, o-VEMP, and c-VEMP, between the VP and non-VP groups. In the literature, changes in these tests were controversial and did not show characteristic results in VP patients $[5,7,10,30]$. Therefore, their potential to predict a neurovascular conflict in VP remains to be discussed. The present study found no difference in the type of vascular loop according to Chavda [20] between the VP group and the non-VP group $(p=0.579)$. Previous studies have demonstrated that there was no statistically significant link between the type of vascular loop and symptoms $[17,29]$. As the type of vascular loop was not the major subject of this study, the correlation between vascular compression loci and VP has to be further evaluated with more nuanced measurement and typing on radiology.

The average age of VP patients was higher than that of non-VP patients. As reported previously, aging may cause vascular stiffening, leading to neurovascular conflict, possibly contributing to the onset of VP [12]. In addition, 76.9\% of the patients had concomitant tinnitus, and all were of the typewriter kind. In contrast, none of the non-VP patients experienced typewriter tinnitus $(p<0.001)$. Our findings replicated the finding of a previous study showing that typewriter tinnitus is highly related to neurovascular compression of the 8th cranial nerve [15]. Mathiesen and Brantberg reported an important case with typewriter tinnitus and neurovascular conflict by MRI on the affected side, underwent microvascular decompression, and had long-term relief of the symptoms. This case suggested that typewriter tinnitus may be a useful indicator of neurovascular contact of the 8th cranial nerve and may be released by surgery [18]. Whether typewriter tinnitus can be used as an indicator for surgical treatment of VP remains to be explored. Most patients in this series of cases had to take medication consistently because vertigo recurred once drug discontinuance occurred at an interval time ranging from a few days to 10 months. It seemed that the symptoms easily relapsed after drug withdrawal in VP patients, so a relatively long-term follow-up was recommended for VP patients.

A limitation of this study was that as a preliminary study, the efficacy of ABR results for indicating neurovascular compression was not proven by surgery. Further studies on this issue are needed and planned in the future.

\section{Conclusion}

The combination of prolonged IPL I-III or wave III latency of $\mathrm{ABR}$ and radiological findings strongly suggested that the MRI-verified vascular loop exerted symptomatic compression on the eighth cranial nerve in VP patients, which might guide the surgeon in decision-making regarding the indication for microvascular decompression in cases when medical therapy alone is not adequate. As the absence of wave I is not rare in VP patients, prolonged wave III latency is considered to serve as an equally significant indicator of VP as IPL I-III.

Supplementary Information The online version contains supplementary material available at https://doi.org/10.1007/s00701-022-05157-2.

Funding This work was supported by Beijing Natural Science Foundation (7222313) and Key Program of Central HPB, National Health and Family Planning Commission of the People's Republic of China (W2016ZD03).

Data availability The datasets generated during and/or analyzed during the current study are available from the corresponding author on reasonable request.

\section{Declarations}

Ethics approval This study was exempted from the Institutional Review Board (IRB) review by the Medical Ethics Committee of Peking Union Medical College Hospital (S-K1695).

Conflict of interest The authors declare no competing interests.

Open Access This article is licensed under a Creative Commons Attribution 4.0 International License, which permits use, sharing, adaptation, distribution and reproduction in any medium or format, as long as you give appropriate credit to the original author(s) and the source, provide a link to the Creative Commons licence, and indicate if changes were made. The images or other third party material in this article are included in the article's Creative Commons licence, unless indicated otherwise in a credit line to the material. If material is not included in the article's Creative Commons licence and your intended use is not permitted by statutory regulation or exceeds the permitted use, you will need to obtain permission directly from the copyright holder. To view a copy of this licence, visit http://creativecommons.org/licenses/by/4.0/.

\section{References}

1. Best C, Gawehn J, Krämer HH, Thömke F, Ibis T, Müller-Forell W et al (2013) MRI and neurophysiology in vestibular paroxysmia: contradiction and correlation. J Neurol Neurosurg Psychiatry 84:1349-1356

2. Bisdorff AR, Staab JP, Newman-Toker DE (2015) Overview of the international classification of vestibular disorders. Neurol Clin 33(541-550):vii

3. Brackmann DE, Kesser BW, Day JD (2001) Microvascular decompression of the vestibulocochlear nerve for disabling positional vertigo: the House Ear Clinic experience. Otol Neurotol 22:882-887

4. Brandt T, Strupp M, Dieterich M (2016) Vestibular paroxysmia: a treatable neurovascular cross-compression syndrome. J Neurol 263(Suppl 1):S90-96

5. Choi SY, Choi JH, Choi KD (2018) The nystagmus of vestibular paroxysmia. J Neurol 265:1711-1713

6. De Ridder D, Heijneman K, Haarman B, van der Loo E (2007) Tinnitus in vascular conflict of the eighth cranial nerve: a surgical 
pathophysiological approach to ABR changes. Prog Brain Res 166:401-411

7. De Ridder D, Ryu H, De Mulder G, Van de Heyning P, Verlooy J, Møller A (2005) Frequency specific hearing improvement in microvascular decompression of the cochlear nerve. Acta Neurochir (Wien) 147:495-501; discusssion 501

8. Han J, Wang T, Xie Y, Cao D, Kang Z, Song X (2018) Successive occurrence of vertebrobasilar dolichectasia induced trigeminal neuralgia, vestibular paroxysmia and hemifacial spasm: a case report. Medicine (Baltimore) 97:e11192

9. Hüfner K, Barresi D, Glaser M, Linn J, Adrion C, Mansmann U et al (2008) Vestibular paroxysmia: diagnostic features and medical treatment. Neurology 71:1006-1014

10. Ihtijarevic B, Van Ombergen A, Celis L, Maes LK, Wuyts FL, Van de Heyning PH et al (2019) Symptoms and signs in 22 patients with vestibular paroxysmia. Clin Otolaryngol 44:682-687

11. Jannetta PJ, Møller MB, Møller AR, Sekhar LN (1986) Neurosurgical treatment of vertigo by microvascular decompression of the eighth cranial nerve. Clin Neurosurg 33:645-665

12. Jannetta PJ, Møller MB, Møller AR (1984) Disabling positional vertigo. N Engl J Med 310:1700-1705

13. Jannetta PJ (1975) Neurovascular cross-compression in patients with hyperactive dysfunction symptoms of the eighth cranial nerve. Surg Forum 26:467-469

14. Jannetta PJ (1977) Observations on the etiology of trigeminal neuralgia, hemifacial spasm, acoustic nerve dysfunction and glossopharyngeal neuralgia. Definitive microsurgical treatment and results in 117 patients. Neurochirurgia (Stuttg) 20:145-154

15. Koo YJ, Kim HJ, Choi JY, Kim JS (2021) Vestibular paroxysmia associated with typewriter tinnitus: a case report and literature review. J Neurol 268:2267-2272

16. Lee JH, Hong S-K, Kim H-J, Lee H-J (2018) Is the auditory brainstem response diagnostic for vestibular paroxysmia? Res Vestib Sci 17:55-59

17. Makins AE, Nikolopoulos TP, Ludman C, O’Donoghue GM (1998) Is there a correlation between vascular loops and unilateral auditory symptoms? Laryngoscope 108:1739-1742

18. Mathiesen T, Brantberg K (2015) Microvascular decompression for typewriter tinnitus-case report. Acta Neurochir (Wien) 157:333-336

19. McCabe BF, Gantz BJ (1989) Vascular loop as a cause of incapacitating dizziness. Am J Otol 10:117-120

20. McDermott AL, Dutt SN, Irving RM, Pahor AL, Chavda SV (2003) Anterior inferior cerebellar artery syndrome: fact or fiction. Clin Otolaryngol Allied Sci 28:75-80
21. Møller MB, Møller AR, Jannetta PJ, Sekhar L (1986) Diagnosis and surgical treatment of disabling positional vertigo. J Neurosurg 64:21-28

22. Møller MB (1990) Results of microvascular decompression of the eighth nerve as treatment for disabling positional vertigo. Ann Otol Rhinol Laryngol 99:724-729

23. Møller AR (1991) The cranial nerve vascular compression syndrome: I. A review of treatment. Acta Neurochir (Wien) 113:18-23

24. Møller MB, Møller AR, Jannetta PJ, Jho HD, Sekhar LN (1993) Microvascular decompression of the eighth nerve in patients with disabling positional vertigo: selection criteria and operative results in 207 patients. Acta Neurochir (Wien) 125:75-82

25. Ryu H, Yamamoto S, Sugiyama K, Nishizawa S, Nozue M (1999) Neurovascular compression syndrome of the eighth cranial nerve. Can the site of compression explain the symptoms? Acta Neurochir (Wien) 141:495-501

26. Sivarasan N, Touska P, Murdin L, Connor S (2019) MRI findings in vestibular paroxysmia - an observational study. J Vestib Res 29:137-145

27. Strupp M, Lopez-Escamez JA, Kim JS, Straumann D, Jen JC, Carey J et al (2016) Vestibular paroxysmia: diagnostic criteria. J Vestib Res 26:409-415

28. Teh CS, Noordiana SH, Shamini S, Prepageran N (2021) Vascular loops: the innocent bystander for vestibular paroxysmia. Ann Otol Rhinol Laryngol:34894211037211. https://doi.org/10.1177/00034 894211037211

29. van der Steenstraten F, de Ru JA, Witkamp TD (2007) Is microvascular compression of the vestibulocochlear nerve a cause of unilateral hearing loss? Ann Otol Rhinol Laryngol 116:248-252

30. Ward BK, Gold DR (2016) Tinnitus, oscillopsia, and hyperventilation-induced nystagmus: vestibular paroxysmia. Open J Clin Med Case Rep 2:1100

31. Yap L, Pothula VB, Lesser T (2008) Microvascular decompression of cochleovestibular nerve. Eur Arch Otorhinolaryngol 265:861-869

32. Yi C, Wenping X, Hui X, Xin H, Xiue L, Jun Z et al (2016) Efficacy and acceptability of oxcarbazepine vs. carbamazepine with betahistine mesilate tablets in treating vestibular paroxysmia: a retrospective review. Postgrad Med 128:492-495

Publisher's note Springer Nature remains neutral with regard to jurisdictional claims in published maps and institutional affiliations. 